\title{
A Study of Noun Phrase Awareness at the Eighth Graders of Two Islamic Junior High Schools in Makassar
}

Awaluddin Syamsu

Universitas Muslim Indonesia

awaluddin.syamsu@umi.ac.id

Article History: First Received: 02/05/2021

Final Revision: $02 / 11 / 2021$

Available online: $30 / 12 / 2021$

\begin{abstract}
Syntactic awareness has been linked to reading comprehension skills. In Junior high schools, syntactic awareness of noun phrases can be very important for the students in the Indonesian context because it can improve their reading comprehension. However, teaching noun phrases for the students can be challenging due to the grammar difference. The junior high school student's noun phrase awareness was measured using a developed test. It consists of 28 questions with seven noun categories. The reliability test was conducted using KR-20 and the result was .90. The study indicated the average score of the students was 69.07 (fair). Of the seven noun phrases category, nominal possessors and conjoined noun phrases were good, prenominal possessors, multiple genitive constructs, alienable and inalienable possessions, and ad-positional phrases were fair, and nonreferential generative was weak. Referring to the result of the research, it is suggested to improve the student's noun phrase awareness to enhance their reading comprehension.
\end{abstract}

Keywords: Noun phrase, syntactic awareness, English lessons, Junior high school

\section{http://jos.unsoed.ac.id/index.php/jes}

\section{INTRODUCTION}

Many researchers have indicated that syntactic awareness positively correlates with the reader's ability to comprehend a reading passage (Mokhtari \& Thompson, 2006; Layton, Robinson, \& Lawson, 1998; Nergis 2013), the higher the reader's awareness of English syntax, the higher the probability to understand a reading text. Syntax research on sentences and their relationship with the ability to understand text has been carried out by Relay (2015) while the cause has been carried out by Kamita (2015). Therefore, research on syntactic awareness at the phrase is necessary to be conducted to understand the issue in a smaller context.

Research on syntactic awareness of the phrase should be started at junior high school or equivalent because at this level schools are required to include English as one 
of the compulsory subjects. At this level, students are taught English ranging from vocabulary to various types of simple sentences.

Junior High School in Indonesia context is commonly abbreviated as SMP (Sekolah Menengah Pertama) for public schools or MTS (Madrasah Tsanawiyah) for Islamic Junior High Schools. However, some SMPs bland their curriculum Islamic subjects such as SMP Muhammadiyah or SMP Datuk Ribandang or other integrated Islamic junior high schools. This indicates that Islamic schools are not only those with the label MTS but other SMPs that include Islamic subjects in their curriculum.

Syntax awareness is very important for junior high school children because it is very important for them to understand their lessons and understand the textbooks which are all written in English. If junior high school students have a good understanding of syntactic awareness, they should have the ability to understand various English texts. By looking at the impact of this syntactic awareness, several experts (Guo, Roehrig, \& Willims, 2011 and Riley, 2015) suggest incorporating this syntactic awareness into the educational curriculum. Therefore, this syntactic awareness is necessary to be divided into various levels such as sentences, clauses, and phrases.

Phrases have many forms; one of the most difficult phrases to learn for Indonesian junior high school students is a noun phrase. This is because the structure of the formation of noun phrases in English is very different from the formation of noun phrases in Indonesian. One example is the phrase "Gadis cantik" in English it is translated as "beautiful girl". The phrase structure in English and Indonesian is different. In the Indonesian Language, the word beautiful (cantik) is modified by gadis (girl) vice versa in English the word girl (gadis) is modified by beautiful (cantik).

\section{Syntactic awareness}

There are various definitions of syntactic awareness put forward by experts. However, for this study the definition used is that syntactic awareness is the ability to understand word sequences and manipulate their structures (Mokhtari \& Thomson, 2006). So in the context of noun phrases, syntactic awareness is the ability to identify and understand the word order in composing noun phrases.

Syntactic awareness facilitates sentence understanding by identifying word connections in a sentence. Furthermore, this concept can help readers to predict the words that will come in the next sentence (Lopez, 2008). Therefore, if the reader has poor syntactic awareness, he will find it difficult to understand the reading text (Lipka \& Siegel, 2012).

Vocabulary mastery plays a very important role in syntactic awareness. The reason is that syntactic awareness cannot work very well if the reader has a very poor level of vocabulary mastery because the first step to improve syntactic awareness is to increase their ability in word order. Another thing is that students must have an understanding of basic sentence grammar; in the context of phrases, they must know the basic grammar rules to form phrases. This basic grammar can help them identify the syntactic structure of phrases. In the structure of English phrases, the adjective comes before the noun while in Indonesian it is placed after the noun, for example, the phrase "beautiful girl" if it is translated to Indonesia the structure will be girl beautiful/gadis cantik.

Syntactic awareness and reading comprehension 
Research into syntactic awareness for educational students shows two different results. Research in China, for example, found syntactic awareness as a predictor of weaker reading comprehension; conversely, vocabulary knowledge has a stronger prediction (Zang, 2012). However, the same study of adults in Turkey had results that showed that syntactic awareness could be a strong predictor of their reading comprehension (Nergis, 2013). Furthermore, in a second language context, August (2006) reported that syntactic awareness has been a strong predictor of reading comprehension attainment.

The conclusion of this difference increases the researcher's curiosity to find out the reasons behind the results of this difference. Riley (2015) reports in her Ph.D. thesis that there are three main reasons why the different results occur: research design, language-related problems, and differences in measurement methods. Furthermore, Kamita (2015) identified that five factors can cause different results in various studies. They are the difficulty level of the text, the difficulty level of the reading task, the linguistic knowledge of the readers (lexical and phoneme), the age of the readers, and the method of assessment.

The investigation of the causes of differences in the results of the above research provides a clue that when giving assignments in measuring eighth-grade students' noun phrases, various important aspects must be considered, including the language factor, in this case, the vocabulary used and how to measure the results. The vocabulary used must take into account the context of eighth-grade junior high school students in which they are taught English as a foreign language.

In the context of foreign language learners, research should go further than finding the relationship between the two constructs to discover what can increase students' syntactic awareness in educational settings and how to do it. One of the things that can be suggested is the background of the native language. This is because several languages share similarities in both words and sentences (Grabe and Stoller, 2011).

Riley (2015) argues the need for practitioners and researchers to develop syntactic models in classroom reading instruction that can facilitate understanding. However, this development can be done after researching the level of syntactic awareness including at the level of primary education, junior high, and high school. Therefore, this study will examine the level of syntactic deficiency of eight / ninth-grade junior high school students. Thus the results can later be used as a basis for proposing appropriate strategies and materials for teaching syntax at the junior high school level.

\section{Syntactic Rules of English and Indonesian}

The use of a syntactic awareness strategy in academic reading is mainly to analyze a sentence. This skill is necessary for foreign language learners because it can assist them to divide a sentence into three categories - subject, verb, and object/complement. This ability can be very helpful in understanding the meaning of a sentence. English and Indonesian are two different languages, but both have a similar structure. The sentence structure is the same, subject, predicate, and object/complement. The major difference is in the phrasal structures.

For simple sentences, English and Indonesian have the same syntactic structure. In this case students would not find it difficult to comprehend the sentence. In the English sentence, it is said that "I love you" in Indonesia the meaning is "Aku suka kamu". I is aku, love is suka, you are kamu. Another example is "I ate cake last night" in Indonesian which can be translated as "Saya makan kue tadi malam". In this example, both the 
syntactic structure and the word order are the same. Apart from similarities, there are some differences. In English, the verb two is used to indicate the past but in Indonesian, the verb for present and past are the same. Past events in the Indonesian Language are marked by an adverb of time which is tadi malam (last night).

Another difference is the word order in a phrase such as in a noun phrase. In English, it says "beautiful girl" but in Indonesian, the word order should be reversed to "Beautiful girl" meaning "gadis cantik". The word order difference in noun phrases becomes one of the challenges for many students because they not only have to understand the meaning of the words in the phrase but also have to understand the grammatical difference of noun phrases between English and Indonesia.

\section{English at grade 8}

In the English handbooks for junior high school students published by the Ministry of Education and Culture (Kementerian Pendidikan dan Kebudayaan, 2017) English lessons at the Junior High School (SMP/MTS) in grades 7 generally are about everyday expressions that are often used in daily spoken English. In addition, the sentences used are short sentences or simple sentences. Although the sentences used are simple, many of them use nominal phrases. The use of these noun phrases has also been seen to be widely used in handbook instruction. In this section, if students want to study independently, students' understanding of syntactic awareness is very important. Furthermore, their syntactic awareness could also help them to understand any text in the handbook.

In the analysis of the teacher's and student's handbooks from The Ministry of Education and Culture, it was found that the handbooks use the English Language. This means students who cannot translate instructions from their handbooks properly will find it difficult to learn independently. In terms of mastery of language, the focus of English instruction at grade 7 is vocabulary, simple grammar, and everyday expressions with their correct pronunciation, and with punctuation marks. Also students learn basic procedural language (Kementerian Pendidikan dan Kebudayaan, 2017).

According to the national curriculum designed by the Ministry of Education and Culture of the Republic of Indonesia (2017), the core of teaching English in grade 8 is expected to develop the students' language skills in understanding short and simple phrases and being able to understand short English texts both orally and written. In this context, students' awareness of phrasal awareness could assist students to have a better understanding.

Thus, the students in the eighth grade are expected to have noun phrase awareness because they have been encountering some noun phrases since they were in the seventh grade. Furthermore, noun phrases are also taught in the 8 grade.

\section{RESEARCH METHOD}

This research employs quantitative research because the results will measure the level of syntactic awareness of eight grades of junior high school students on noun phrases. The measurement was conducted by designing a test that will be first tested for its reliability using the KR-20 formula. Then the data collected from this test had been categorized and interpreted.

The research was conducted in the city of Makassar, South Sulawesi, Indonesia. The research took place in two Islamic junior high schools: one is labeled as MTS the 
other one is SMP that includes Islamic subjects in their curriculum. These two schools accepted the research to be conducted on their students. In the MTS, the questionnaire was administered under the supervision of the English teacher and counseling unit whereas, in the SMP, the questionnaire was administered under the English teacher supervision.

Of the 4 classes that we distributed at the MTS, 66 students filled out the test while in the SMP 34 students answered our test. So that our total respondents were 100 Islamic junior high school students.

The two junior high schools were chosen because they have an A accreditation. Secondly, the school staff was ready to help us to research the Covid-19 era where all students had to learn from home.

The time for distributing the test was one week before the final school exams, so it can be assumed that the learning in the eighth grade has been completed.

C. Data Collection, Processing, and Analysis

The process of collecting and analyzing data was carried out by designing a noun phrase test. This test had been tested for its reliability using the KR-20 formula.

$$
\mathrm{KR} .20=\frac{\mathrm{K}}{\mathrm{K}-\mathrm{l}}\left[\frac{\mathrm{S}_{\mathrm{x}}{ }^{2}-\sum_{\mathrm{P}_{\mathrm{i}}\left(1-\mathrm{P}_{\mathrm{i}}\right)}}{\mathrm{S}_{\mathrm{x}}{ }^{2}}\right]
$$

The calculation result of this reliability is expected to KR.20> 7.0 because the level of reliability of a test to obtain reliable results is greater than 7.0.

After administering the test, the results will be grouped into five categories, namely excellent, good, fair, weak, and fail which are based on the following guideline:

Table 1. Score Category Guideline

\begin{tabular}{|l|l|l|}
\hline \multicolumn{1}{|c|}{ Score } & \multicolumn{1}{|c|}{ Marks } & \multicolumn{1}{|c|}{ Explanation } \\
\hline $90-100$ & High Distinction/excellent & $\begin{array}{l}\text { Demonstrates a complete } \\
\text { understanding of the problem. all } \\
\text { requirements of th task are } \\
\text { included in the response }\end{array}$ \\
\hline $70-89$ & Distinction/good & $\begin{array}{l}\text { Demonstrates considerable } \\
\text { understanding of the problem. all } \\
\text { requirements of the task are } \\
\text { included }\end{array}$ \\
\hline $60-69$ & Credit/fair & $\begin{array}{l}\text { Demonstrate partial understanding } \\
\text { of the problem. most requirements } \\
\text { of the task are included }\end{array}$ \\
\hline $50-59$ & Pass/weak & $\begin{array}{l}\text { Demonstrating little understanding } \\
\text { of the problem. many requirements } \\
\text { of task are missing }\end{array}$ \\
\hline$>50$ & Femonstrating no understanding \\
\hline
\end{tabular}

(Bailey, 1998)

The process of collecting and analyzing data was carried out in the following stages:

1. Designing a test to measure the syntactic awareness level of noun phrases of the eighth grade of junior high school students. 
2. Conducting reliability tests.

3. Distributing the test to junior high school students.

4. Analyzing the data gathered from the designed noun phrase test.

5. Interpreting the data

6. Reporting the findings

\section{RESULT AND DISCUSSION}

This study uses a new measuring tool because there is a test that can be used to measure the syntactic awareness of students at the junior high school on noun phrases. The results of the reliability test of 28 questions given to junior high school students using the Kuder Richardson 20 formula were 0.902. Based on this value, it can be said that the reliability was very good because the value is greater than 0.9 and also did not exceed 0.95. These results indicated that the test was reliable and can be administered.

The test was distributed to 4 classes in MTS and 2 classes in SMP. The test in MTS was responded to by 66 students consisting of 20 male and 46 female students whereas at SMP there were 34 respondents with 13 boys and 31 girls so that the total respondents were 100 students with 33 males and 77 females.

The results of the test from 100 respondents are as follows:

Table 2. Tested Word and Result

\begin{tabular}{llcc}
\hline $\mathbf{N o}$ & Words & $\begin{array}{c}\text { Correct } \\
\text { Answers } \\
\mathbf{( \% )}\end{array}$ & $\begin{array}{c}\text { Incorrect } \\
\text { answers } \\
(\boldsymbol{\%})\end{array}$ \\
\hline $\mathbf{1}$ & the-country-man & 70 & 30 \\
$\mathbf{2}$ & new-family-his & 80 & 20 \\
\hline $\mathbf{3}$ & sister's-friend-my & 67 & 33 \\
\hline $\mathbf{4}$ & sister-my-elder & 66 & 34 \\
\hline $\mathbf{5}$ & female-a-hat & 63 & 37 \\
\hline $\mathbf{6}$ & student-as-a & 70 & 30 \\
\hline $\mathbf{7}$ & boy's-the-books & 69 & 31 \\
\hline $\mathbf{8}$ & teacher-my-beautiful & 65 & 35 \\
\hline $\mathbf{9}$ & father's-his-books & 58 & 42 \\
\hline $\mathbf{1 0}$ & John's-nose-big & 54 & 46 \\
\hline $\mathbf{1 1}$ & the-house-inside & 52 & 48 \\
\hline $\mathbf{1 2}$ & their-books-new & 71 & 29 \\
\hline $\mathbf{1 3}$ & now-on-from & 51 & 49 \\
\hline $\mathbf{1 4}$ & room-in-the & 90 & 10 \\
\hline $\mathbf{1 5}$ & friends-our-good & 57 & 43 \\
\hline $\mathbf{1 6}$ & Ahmad's-a-cousin-of & 75 & 25 \\
\hline $\mathbf{1 7}$ & the-Makassar-mayor-of & 82 & 18 \\
\hline $\mathbf{1 8}$ & man's-brother-the-elder & 42 & 58 \\
\hline $\mathbf{1 9}$ & Awal's-parents-the-of & 67 & 33 \\
\hline $\mathbf{2 0}$ & the-body-top-my-of & 84 & 16 \\
\hline $\mathbf{2 1}$ & man-a-woman-and-a & 87 & 13 \\
\hline $\mathbf{2 2}$ & the-head-boy-of-the & 85 & 15 \\
\hline & & & \\
\hline & & & 13 \\
\hline
\end{tabular}




\begin{tabular}{llcc}
\hline $\mathbf{2 3}$ & boys-my-two-friend-of & 52 & 48 \\
\hline $\mathbf{2 4}$ & book-and-your-book-my & 92 & 8 \\
\hline $\mathbf{2 5}$ & students-this-of-some-school & 52 & 48 \\
\hline $\mathbf{2 6}$ & and-a-car-a-bicycle & 83 & 17 \\
\hline $\mathbf{2 7}$ & choices-my-of-mother-any & 63 & 37 \\
\hline $\mathbf{2 8}$ & parents-your-and-my-parents & 87 & 13 \\
\hline & Average & 69.07 & 30.93 \\
\hline
\end{tabular}

From this data, it can be seen that the overall ability of Islamic junior high school students in composing nominal phrases. Their abilities in each type of noun phrase are as follows:

Table 3. Table Generative constructive with nominal possessors

\begin{tabular}{cccc}
\hline No & Words & $\begin{array}{c}\text { Correct } \\
\text { Answer } \\
(\mathbf{\%})\end{array}$ & $\begin{array}{c}\text { Incorrect } \\
\text { Answer } \\
(\mathbf{\%})\end{array}$ \\
\hline $\mathbf{1}$ & the-country-man & 70 & 30 \\
\hline $\mathbf{7}$ & boy's-the-books & 69 & 31 \\
\hline $\mathbf{1 7}$ & the-Makassar-mayor-of & 82 & 18 \\
\hline $\mathbf{2 2}$ & the-head-boy-of-the & 85 & 15 \\
\hline \multicolumn{4}{r}{} \\
\hline
\end{tabular}

Table 4. Prenominal possessors

\begin{tabular}{llcc}
\hline No & Words & $\begin{array}{c}\text { Correct } \\
\text { Answer } \\
(\boldsymbol{\%})\end{array}$ & $\begin{array}{c}\text { Incorrect } \\
\text { Answer } \\
(\boldsymbol{\%})\end{array}$ \\
\hline $\mathbf{2}$ & new-family-his & 80 & 20 \\
\hline $\mathbf{8}$ & teacher-my-beautiful & 65 & 35 \\
\hline $\mathbf{1 2}$ & their-books-new & 71 & 29 \\
\hline $\mathbf{1 5}$ & friends-our-good & 57 & 43 \\
\hline & Average & 68.25 & 33.75 \\
\hline
\end{tabular}

Table 5. Multiple genitive construct

\begin{tabular}{llcc}
\hline No & Words & $\begin{array}{c}\text { Correct } \\
\text { Answer } \\
(\boldsymbol{\%})\end{array}$ & $\begin{array}{c}\text { Incorrect } \\
\text { Answer } \\
(\boldsymbol{\%})\end{array}$ \\
\hline $\mathbf{3}$ & sister's-friend-my & 67 & 33 \\
\hline $\mathbf{9}$ & father's-his-books & 58 & 42 \\
\hline $\mathbf{1 6}$ & Ahmad's-a-cousin-of & 75 & 25 \\
\hline $\mathbf{1 9}$ & Awal's-parents-the-of & 67 & 33 \\
\hline & Average & 66.75 & 34.25 \\
\hline
\end{tabular}


Table 6. Alienable and inalienable possessions

\begin{tabular}{llcc}
\hline $\mathbf{N o}$ & Words & $\begin{array}{c}\text { Correct } \\
\text { Answer } \\
(\mathbf{\%})\end{array}$ & $\begin{array}{c}\text { Incorrect } \\
\text { Answer } \\
(\boldsymbol{\%})\end{array}$ \\
\hline $\mathbf{4}$ & sister-my-elder & 66 & 34 \\
\hline $\mathbf{1 0}$ & John's-nose-big & 54 & 46 \\
\hline $\mathbf{1 8}$ & man's-brother-the-elder & 42 & 58 \\
\hline $\mathbf{2 0}$ & the-body-top-my-of & 84 & 16 \\
\hline & Average & 61.5 & 40.5 \\
\hline
\end{tabular}

Table 7. Nonreferential genitives

\begin{tabular}{llcc}
\hline No & Words & $\begin{array}{c}\text { Correct } \\
\text { Answer } \\
(\boldsymbol{\%})\end{array}$ & $\begin{array}{c}\text { Incorrect } \\
\text { Answer } \\
(\boldsymbol{\%})\end{array}$ \\
\hline $\mathbf{5}$ & female-a-hat & 63 & 37 \\
\hline $\mathbf{2 3}$ & boys-my-two-friend-of & 52 & 48 \\
\hline $\mathbf{2 5}$ & students-this-of-some-school & 52 & 48 \\
\hline $\mathbf{2 7}$ & choices-my-of-mother-any & 63 & 37 \\
\hline & Average & 57.5 & 42.5 \\
\hline
\end{tabular}

Table 8. Adpositional phrases

\begin{tabular}{llcc}
\hline $\mathbf{N o}$ & Words & $\begin{array}{c}\text { Correct } \\
\text { Answer } \\
(\boldsymbol{\%})\end{array}$ & $\begin{array}{c}\text { Incorrect } \\
\text { Answer } \\
(\boldsymbol{\%})\end{array}$ \\
\hline $\mathbf{6}$ & student-as-a & 70 & 30 \\
\hline $\mathbf{1 1}$ & the-house-inside & 52 & 48 \\
\hline $\mathbf{1 3}$ & now-on-from & 51 & 49 \\
\hline $\mathbf{1 4}$ & room-in-the & 90 & 10 \\
\hline & Average & 65.75 & 34.25 \\
\hline
\end{tabular}

Table 9. Conjoined noun phrase

\begin{tabular}{llcc}
\hline No & Words & $\begin{array}{c}\text { Correct } \\
\text { Answer } \\
(\mathbf{\%})\end{array}$ & $\begin{array}{c}\text { Incorrect } \\
\text { Answer } \\
(\boldsymbol{\%})\end{array}$ \\
\hline $\mathbf{2 1}$ & man-a-woman-and-a & 87 & 13 \\
\hline $\mathbf{2 4}$ & book-and-your-book-my & 92 & 8 \\
\hline $\mathbf{2 6}$ & and-a-car-a-bicycle & 83 & 17 \\
\hline $\mathbf{2 8}$ & parents-your-and-my-parents & 87 & 13 \\
\hline & Average & 87.25 & 12.75 \\
\hline
\end{tabular}


Based on the results of the test, it can be said that the overall average ability of students in syntactic awareness of noun phrases is 69.07 or fair. This means MTS and SMP students have a limited understanding of noun phrases. The students already have an idea about noun phrases even though they cannot apply them correctly in varied contexts. One of the reasons could be their lack of vocabulary mastery because lack of vocabulary will lead to difficulty in understanding the meaning of noun phrases (Zang, 2012).

The interesting thing is when the ability of this noun phrase is examined in more detail, it can be seen that the conjoined noun phrase has the highest average score, namely 87.25. This means students have a good understanding already. Meanwhile, the lowest score was a nonrefrential generative noun phrase, which was 57.5 , or it could be interpreted that the students' understanding is weak. They do not have a good ability to compose and understand the meaning of the noun phrase.

According to Bailey (1997), students who are at a weak level do not have a good ability to recognize and tend to make mistakes from the concept being assessed while fair means that they already understand the concept they want to measure but it was not good enough, and a good level means that students have a good understanding of the concepts being tested even though there are still a few shortcomings. Therefore, increasing the noun phrase awareness of the students is necessary. It is because the student will find it difficult to understand a text if they have poor syntactic awareness (Likpka \& Siegel, 2012).

Of the seven types of tested noun phrases: generative constructive with nominal possessors, prenominal possessors, multiple genitive constructs, alienable and inalienable possessions, nonreferential genitives, adpositional phrases, conjoined noun phrases, the results can be divided into three groups: 50-59 (weak), 60-69 (fair), 70-89 (good). Only one is in the weak level, non-referential genitives (57.5). Four are in fair ability: prenominal possessors (68.25), multiple genitive construct (66.75), alienable and inalienable possessions (61.4), and adpositional phrases (65.75). The other two are the nominal possessors (76.5) and the conjoined noun phrase (87.25) are good. This interesting data indicates that students in the Islamic schools with an A accreditation generally have an awareness of the seven types of noun phrases because of the seven types of tested noun phrases, there is no one where students' average score is less than 50.

The awareness of the students on the noun phrases could be learned from their lessons in the 7 and 8 grades. In their handbooks published by the Ministry of Education and Culture (2017), it was found that noun phrases in grade 7 found for example my favorite food, my elder brother, next to the bank, and a roper statement whereas some other examples of noun phrases can be also found in grade 8 handbooks such as the heaviest land animal, different kinds of public transportation, in a small village, Udin's birthday.

However, referring to the result of the test, students' awareness should be improved to increase the comprehension of their lessons. In the eighth grade, students learn more about reading and conversation. In these lessons, their noun phrase awareness could assist them to perform better comprehension, especially in reading. According to previous studies, syntactic awareness would assist readers to comprehend reading text (Mokhtari \& Thompson, 2006; Layton, Robinson, \& Lawson, 1998; Nergis 2013). 


\section{CONCLUSION}

English noun phrases have different structures if they are translated into the Indonesian Language. This difference could make it difficult for the students to understand noun phrases' meaning. Syntax awareness will be very helpful in understanding a text for foreign language learners. At the SMP / MTS level, syntactic awareness is at the level of noun phrases because the use of these phrases has often been found in student handbooks. Thus, if they have a good syntactic awareness it could assist their learning.

The results showed that the general syntax level of students for their noun phrases was 69.07 or at a fair level, meaning that on average students had difficulty in compiling and understanding English noun phrases. In detail, of the seven types of tested nominal phrases one is weak (non-referential generative), four are fair (prenominal possessors, multiple genitive constructs, alienable and inalienable possessions, and adpositional phrases), and two are good (nominal possessors and conjoined noun phrases). None of the average values of the seven types of terminal phrases are at a very low level, which is below the number 50 and none are at numbers above 90 .

Noun phrases have been found in the 7 and 8-grade students' handbooks. This means students will still find it difficult to understand English noun phrases, therefore it is necessary to increase their syntactic awareness of noun phrases because the better the level, the easier it is for them to understand their lessons.

\section{REFERENCES}

August, G. (2006). So what's behind adult English second language reading? Bilingual Research Journal, 30(2), 245-264.

Baylei, K. (1998). Learning about Language Assessment: Dilemmas, Decisions, and Directions. Heinle \& Heinle. Boston

Grabe, W., \& Stoller, F. (2011). Teaching and Researching Reading. Harlow, UK: Pearson Educational Limites.

Kamita, H. (2015). An Investigation of the Relationship between Japanese University Students' English Syntactic Awareness and Their Use of Cognitive and Metacognitive Reading Strategies. University of Southern Queensland, Queensland, Australia.

Kementerian Pendidikan dan Kebudayaan Republik Indonesia. (2017). Buku Siswa: When English Rings a Bell Kelas 8. Jakarta, Indonesia

Kementerian Pendidikan dan Kebudayaan Republik Indonesia. (2017). Buku Siswa: When English Rings a Bell Kelas 7. Jakarta, Indonesia

Kutner, M., Greenberg, E., \& Baer, J. (2006). National Assessment of Adult Literacy (NAAL): A first look at the literacy of America's adults in the 21st century (Report No. NCES 2006-470). Washington, DC: U.S. Department of Education, National Center for Education Statistics.

Lipka, O., \& Siegel, L. (2012). The development of reading comprehension skills in children learning English as a second language. Reading and Writing, 25, 18731898.

López, Á. L. (2008). To what extent does grammar knowledge account for competence in FL reading comprehension in university students? RESLA, 21, 181-200. 
Mokhtari, K., \& Thompson, H. B. (2006). How problems of reading fluency and comprehension are related to difficulties in syntactic awareness skills among fifth graders. Reading Research and Instruction, 46(1), 73-94.

Nassaji, H. (2014). The role and the importance of lower-level process in second language reading. Language Teaching, 47(1), 1-37

Nergis, A. (2013). Exploring the factors that affect reading comprehension of EAP learners. Journal of English for Academic Purpose, 12(1),1-9

Riley, Q. Z. (2015). A Quasi Experimental Study on The Effect of Syntactic Awareness Instruction on Reading Comprehension of Adult English Learners. Northcentral University, Arizona, The USA.

Zang, D. (2012). Vocabulary and grammar knowledge in second language reading comprehension: A structural equation modelling study: The Modern Language Journal, 96, 558-575. 